\title{
MAGAM: A Multi-Aspect Generic Adaptation Model for Learning Environments
}

\author{
Baptiste Monterrat ${ }^{1}$, Amel Yessad ${ }^{1}$, François Bouchet ${ }^{1}$, \\ Élise Lavoué ${ }^{2}$, Vanda Luengo ${ }^{1}$ \\ ${ }^{1}$ Sorbonne Universités, UPMC Paris 6, CNRS, LIP6 UMR 7606, Paris, France \\ \{baptiste.monterrat, amel.yessad, francois.bouchet, vanda.luengo\}@lip6.fr \\ ${ }^{2}$ IAE Lyon, Université Jean Moulin Lyon 3, LIRIS UMR CNRS 5205, France \\ elise.lavoue@univ-lyon3.fr
}

\begin{abstract}
Adaptation in learning environments can be performed according to various aspects, such as didactics, pedagogy or game mechanics. While most current approaches propose to adapt according to a single aspect, this paper proposes a Multi-Aspect Generic Adaptation Model (MAGAM). Based on the Q-matrix, this model aims at taking into account heterogeneous data to select adapted activities. It has been implemented and used into an experiment which allowed the adaptation of learning activities for 97 students based on both knowledge and gaming profiles. This experiment has shown the usefulness of MAGAM to combine various aspects of adaptation in ecological conditions.
\end{abstract}

Keywords. Adaptation, Learner model, Recommender system.

\section{Introduction}

Adaptive systems are often defined by three characteristics: (1) the source (what will it adapt to), (2) the target (what will be adapted) and (3) the pathway (how to adapt the target to the source). In this paper, we call the combination between the source and the target an aspect of adaptation. For an adaptation to be successful, the source should bring information that is relevant with regard to the target. For example, a system adapting didactic contents relies on cognitive profiles, while a system adapting the game mechanics of a serious game relies on player profiles.

In a review of the state of the art of adaptation for learning, Vandewaetere et al. [1] identified over ten sources of adaptation, such as the learners' knowledge and culture, and over twenty targets of adaptation such as content and feedback. However, most proposed systems in the literature are limited to one aspect of adaptation. The diversity of adaptation technics could be an explanation for this limitation. Indeed, Vandewaetere et al. [1] also identified over twenty pathways such as rule-based systems or Bayesian networks. This wealth of techniques could also be the reason why Naik \& Kamat [2] think it is not feasible to take into account a large number of sources for adaptation. However, we believe a multi-aspect adaptation is not only advisable but also feasible if it is supported by a model designed to be generic enough.

We make the hypothesis that a model with generic variables and operators could federate different aspects of adaptation. To this end, we developed a model called MAGAM (Multi-Aspect Generic Adaptation Model) which relies on properties that are common to the learners and to the activities to be adapted. After a brief state of 
the art of adaptation techniques in section 2, we present this model in section 3 . Then we present in section 4 an experiment performed to evaluate the model and its usage.

\section{Approaches for Adaptation of Learning Environments}

\subsection{The Adaptation Loops}

Aleven et al. [3] distinguish three types of adaptation loops: design, task and step. The design loop adaptation relies on an analysis of the learner and learning data that is taken into account for new design iterations. In task loop adaptation, the system has to select the task that suits best the learner. Finally, the step loop is responsible for several adaptations within a task, in reaction to the learner's actions. Systems based on the design loop adapt the learning design to the common characteristics of learners, while systems based on the task and step loop adapt to the differences between learners. The model we present here is developed mainly for the task loop.

The adaptation loops rely on two operations: selecting/setting the activities adapted to the learners, and initializing/updating the learners' profiles. The model we propose applies to selecting/setting activities. It can be used in conjunction with various methods for initializing/updating the learners' profiles - a point not considered here.

\subsection{Aspects of Adaptation}

Several types of sources have been found to positively impact learning outcomes. Through a literature review, Aleven et al. [3] classified into five categories the sources that have been experimentally validated: (1) knowledge, (2) problem-solving strategies and errors, (3) affect and motivation, (4) self-regulated learning and metacognition and (5) learning styles. We detail here six aspects of adaptation, five of which are related to these sources. We consider the gaming profile as another aspect of adaptation.

Didactic Aspect. The learner's knowledge level was one of the first lines of research for adaptation. In 1972, Atkinson [4] improved the students' performances in language learning by selecting their tasks according to their previous answers. In 1995, Anderson et al. [5] proposed Cognitive Tutor, a system that evaluates the knowledge state of a learner, represented in a Bayesian network. The model is then used to select the tasks not mastered by the learner, leading to a better improvement of the students' performances than when no model is used. Other kinds of knowledge dimensions may be considered for adaptation. For example, Luengo et al. [6] consider the nature of the knowledge (e.g. perception, gesture, procedural) to adapt the learning task in orthopedic surgery based on a didactical analysis implemented by a Bayesian network.

Pedagogic Aspect. Melero et al. [7] proposed a system that recommends activities of a serious game to the learners. It takes into account both the learner's cognitive profile 
and teaching strategies (advancing, reinforcing and deepening) set by the teachers. This system relies on the Competence-based Knowledge Space Theory (CbKST) [8] to identify the space of knowledge states learners go through. Field experiments showed a concordance between the teachers' choices and those of the adaptation system.

Affective and Motivational Aspect. Walkington [9] developed an environment for learning algebra that adapts to the learners' interests. This system has enabled learners to better understand the problems and to obtain better results. In their research on the links between personality and emotions, Harley et al. [10] also made several proposals to make learning environments adapted to emotions, in particular to reduce anxiety.

Strategic Aspect. In MetaTutor [11], a learning environment designed to encourage students to deploy self-regulated learning strategies, pedagogical agents' interventions are triggered by a rule-based system to encourage students to use these processes at the appropriate moment. Experimental evaluations have shown that students who received agents' prompts obtained better results than students who did not.

Learning Styles Aspect. Mampadi et al. [12] worked on two learners' cognitive styles: holistic and serialist. In their experiment, participants who learned using an environment adapted to their cognitive style performed better than those in the control group. Learners' profile can be initialized through a questionnaire [12] or through an automatic detection of learning styles from learners' traces [13].

Gaming Aspect. Proposals for adaptation among the gaming aspect appear less often in literature reviews, although some experiments gave positive results. Natkin et al. [14] made one of the first proposals of game mechanics adaptation. They relied on personality types (e.g. introvert, resilient) to select quests in a serious game which mechanics were adapted to the players. Inspired by their method, Monterrat et al. [14] developed an adaptive system to gamify an existing learning environment. They relied on player types (e.g. socializer, achiever [16]) to select gamification features adapted to the students. During an experiment with 223 learners, those with adapted elements used more the environment than those with a counter-adapted environment.

\subsection{Multi-Aspect Adaptation}

Some articles report research based on a multi-aspect adaptation. Heilman et al. [17] present a system that considers both the learners' interests and competences. It was evaluated in an English vocabulary course with 22 learners and showed positive results on the learners' performance. As another example, the system proposed by Yarandi et al. [18] adapts the learning path based on learners' knowledge model and the presentation based on their learning styles, abilities and preferences. These systems are not easily generalizable, as they are specific to the combined aspects and their related adaptation techniques. 
For a more generic approach, Murray et al. [19] propose an approach based on decisions theory to model adapted pedagogical actions. This approach uses a Bayesian dynamic decision network to model tutor actions and several student adaptation aspects (knowledge, focus and affect, ibid. p 241). The authors evaluate (with historical data) one or two dimensions of the decision network in the framework of tutoring systems. Even if the model is generic enough, the problem of tractability is still a challenge. Indeed the model can include hundreds of nodes, their specification and calibration is difficult and not accessible to non-experts. In addition, the tutor actions are still dependent of the system.

In gaming contexts, Göbel et al. [20] proposed a model that uses both a didactic adaptation model based on learners' knowledge and a gaming adaptation model based on learners' player types. They propose a weight system to merge the two aspects at the same time to choose an activity. The model presented in this paper can be seen as a generalization of the one proposed by Göbel et al. [20].

\section{MAGAM: Presentation of a Multi-Aspect Generic Model}

In this section, we present MAGAM (Multi-Aspect Generic Adaptation Model). This model is based on three entities: the users-learners (U), the pedagogic activities (A) and the properties $(\mathrm{P})$ applied to both users and activities.

\subsection{A Generic Model}

The main goal of the adaptation model is to propose activities adapted to each learner according to several aspects. Each aspect is embodied in a set of properties. The properties are linked (1) to the users through a system of values with their own semantic, and (2) to the activities with another semantic and system of values. For example:

- If the properties are skills (e.g. add, multiply), the values can express the level of mastery of the user in each skill on the one hand, and express how well the activity helps learning each skill on the other hand.

- If the properties are game mechanics (e.g. competition, exploration), the values can express how much the user appreciates these mechanics on the one hand, and to what degree the activity includes these mechanics on the other hand.

To visualize the model, we propose a representation on the three visible faces of a cuboid (see Fig. 1). The user profile is the set of values that link the properties to the user, represented into the matrix $M$. The values that link the properties to the activities are represented into the matrix Q. Finally, the system provides a recommendation matrix called $\mathrm{R}$ representing how well each activity is adapted to each learner. 


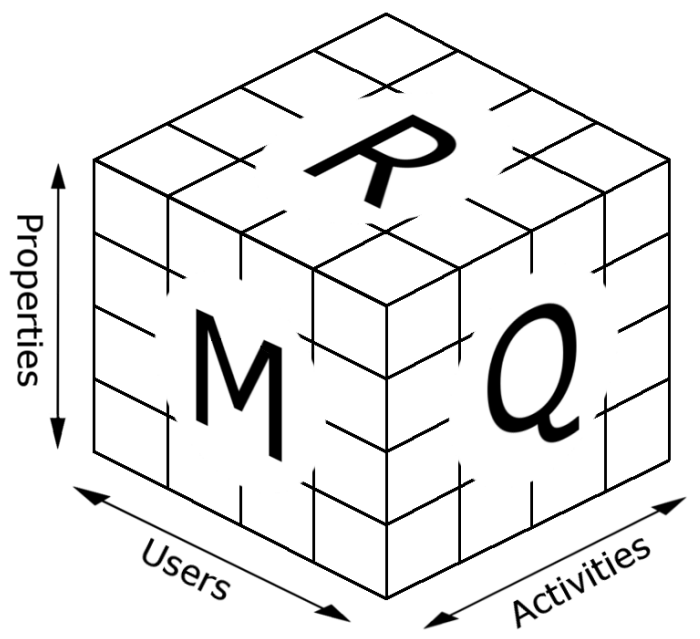

Fig. 1. Three-dimensional representation of MAGAM.

The values of the user profiles $(\mathrm{M})$ can be collected using various methods, such as questionnaires or interaction traces analysis, either in real time or from previously collected data. Matrix Q is inspired by the Q-matrix of Barnes [18], but it can apply to other aspects than skills and contain other values than 0 and 1. There are also several ways to obtain the matrix Q, such as relying on domain experts [14] or data analysis [22]. To obtain the recommendation matrix, we define a Calculation (eq. 1), denoted $\mathrm{C}$, as an application that builds $\mathrm{R}$ from $\mathrm{Q}$ and $\mathrm{M}$ :

$$
\mathrm{C}(\mathrm{Q}, \mathrm{M}) \rightarrow \mathrm{R}
$$

Several examples from the literature described in section 2.2 are compatible and can be described as use cases of MAGAM. As previously mentioned, in [11] (see Fig. 2 ), the learners were classified according to whether they were holist or serialist. We can represent these two sides of the same personality trait as one property with the value 1 (Holist) or -1 (Serialist). The matrix $M$ represents the results of the personality survey. In some cases, the model can recommend characteristics of the learning environment rather than activities. In this case, the adaptive characteristics of the activities were (1) next/previous buttons, (2) hyperlinks, (3) a hierarchical map and (4) an index. The matrix Q links these characteristics with the personality traits (e.g. a holistic user would prefer content that is structured as a hierarchical map). Finally, a calculation provides the matrix R, that contains 1 when the activity matches the learner's profile and 0 when it does not. 


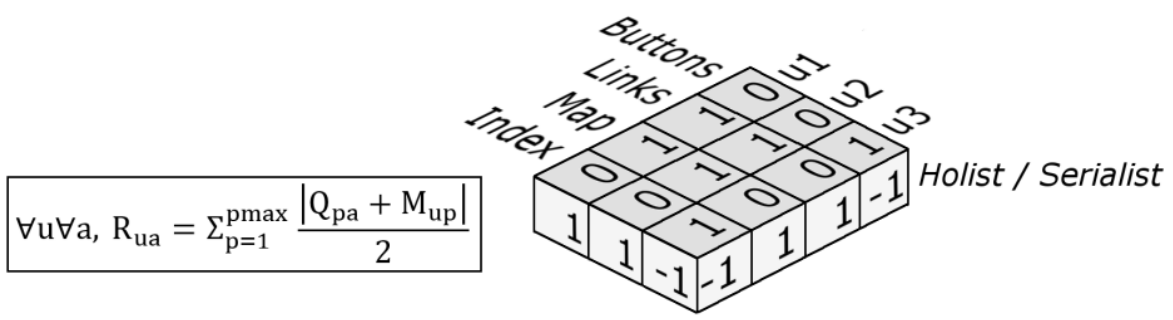

Fig. 2. Representation of the adaptation system in [11] through MAGAM.

Walkington [8] gave students algebra problems based on the users' interests. 27 algebra problems were developed, with 4 versions for each corresponding to different interests, which makes 108 activities in total. The authors do not provide the details of the calculation, however when applying MAGAM, a calculation can be deduced from their adaptation logic. We propose on Fig. 3 a possible representation of their adaptation system (calculation $\mathrm{C}_{1}$ ). It includes four problems that belong to three different types of interests, and assumes the survey provided scores from zero to five.

The model used by Natkin et al. [13] is also compatible with MAGAM. Their adaptation is based on the Five Factor Model [23], composed of five dimensions expressed in values from -1 to 1 for both users and activities. The recommendation comes from a distance measurement between the vector of the user and the vector of the activity. We can express this distance with a calculation in MAGAM. It is shown in Fig. 3 (calculation $\mathrm{C}_{2}$ ).

\subsection{Merging for a Multi-Aspect Adaptation}

The calculation system described in the previous section builds an adaptation on several properties that belong to the same aspect. To build an adaptation on several aspects, we need to combine the recommendations obtained from different calculations. To this end, we define the merGer (eq. 2) as an application that builds a matrix R from other matrices Ri.

$$
\mathrm{G}(\mathrm{R} 1, \mathrm{R} 2, \ldots, \mathrm{Rn}) \rightarrow \mathrm{R}
$$

Several types of calculations can be used as a merger. For example, we can take a weighted average of the matrices as proposed by Göbel et al. [20]. Alternately we can take the minimum for each value. Thus, if a calculation gives a very low value in Ri, then it is sure this low value will persist in the final matrix $R$, which prevents selecting activities evaluated as unsuitable on one aspect. We can also take the maximum of each value to select activities that suit the user very well on, at least, one of the aspects.

Finally, to identify which activity will be recommended to the learner, we define the Selection (eq. 3) as an application that builds a one-column matrix R' from R. The matrix R' contains the id of each activity that has been selected for each user.

$$
\mathrm{S}(\mathrm{R}) \rightarrow \mathrm{R}^{\prime}
$$


To illustrate the possibilities of mergers, Fig. 3 represents an example of application of MAGAM including three calculations: by the motivational aspect $\left(\mathrm{C}_{1}\right)$, by the gaming aspect $\left(\mathrm{C}_{2}\right)$ and by the pedagogical aspect $\left.\mathrm{C}_{3}\right)$.

The first calculation is derived from [8] and the second from [13]; they are described in details in section 3.1. For the third calculation, we propose to apply a pedagogical constraint by considering the learner's available time. In matrix $M$, the user expresses how much time (in minutes) he/she had for the learning session. The matrix Q represents how much time is required to complete each activity. We design a calculation that rejects activities longer than the user's available time and accepts shorter ones. Fig. 3 shows that the activity a1 takes 8 minutes, it suits extroverts and talks about music.

Firstly, we merge $R_{C 1}$ and $R_{C 2}$ into $R_{G 1}$ by taking the average values, giving them the same weight. Secondly, we merge $\mathrm{R}_{\mathrm{G} 1}$ and $\mathrm{R}_{\mathrm{C} 3}$ into $\mathrm{R}_{\mathrm{G} 2}$ by taking the product of the values. Indeed, a zero value in $\mathrm{R}_{\mathrm{C} 3}$ means the corresponding activity cannot be done by the user and merging with the product of values maintains the zeros into the final R.

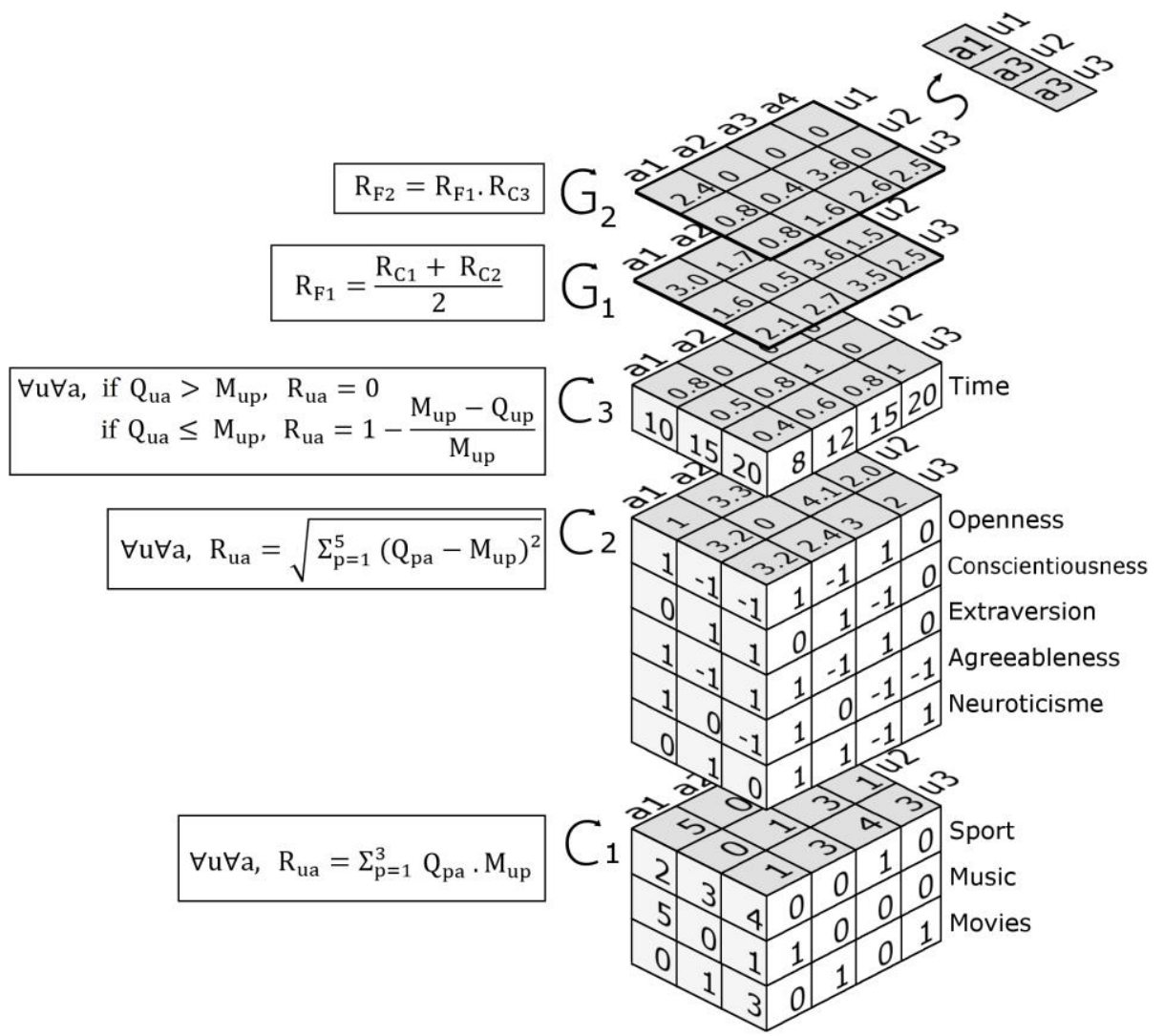

Fig. 3. Example of successive mergers. 


\subsection{Implementation of MAGAM}

We implemented the MAGAM framework using web technologies (HTML, MySQL, PHP), with an interface allowing to manually specify the entities, write the values in the matrices $\mathrm{M}$ and $\mathrm{Q}$, choose the operations and finally read the results of the adaptation (see Fig 4).

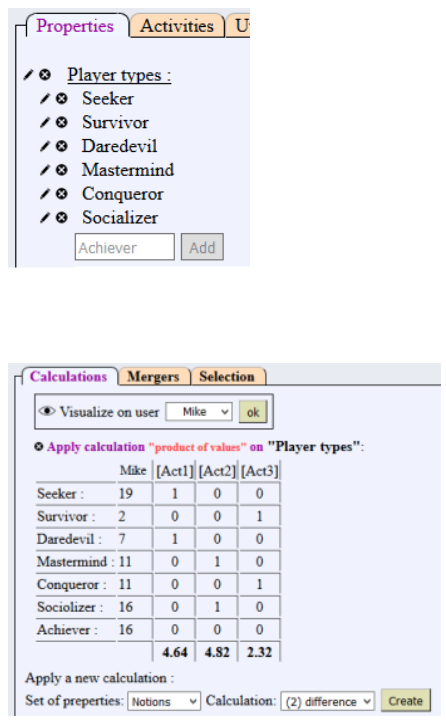

\begin{tabular}{|c|c|c|c|c|}
\hline \multicolumn{5}{|c|}{ Activities' profiles Users' profiles } \\
\hline & [Mike] & [Brian] & [Megan] & [Lili] \\
\hline Seeker & $19=$ & $16 \div$ & 0,5 - & $17 \div$ \\
\hline Survivor & $2=$ & $-3=$ & $7 \div$ & $-3 \leqslant$ \\
\hline Daredevil & $7 \div$ & $1 \div$ & $0 \leqslant$ & $1 \leqslant$ \\
\hline Mastermind & $11 \leqslant$ & $19 \leqslant$ & $13 *$ & 16 ิ \\
\hline Conqueror & $11 \triangleq$ & $11 \leqslant$ & $17 \leqslant$ & $11 \leqslant$ \\
\hline Sociolizer & $16 \triangleq$ & 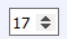 & $14 \div$ & $17 \div$ \\
\hline Achiever & $16 \triangleq$ & $14=$ & $20 \leqslant$ & $13 \leqslant$ \\
\hline
\end{tabular}

Fig. 4. Screenshot extracts from an implementation of MAGAM.

Left: page to createledit a list of properties.

Middle: page to edit the values of matrix $M$.

Right: page to apply a calculation and visualizing the results for one user.

\section{Experiment}

We organized a four-week experiment to evaluate MAGAM and its implementation. The experiment proposed a didactic and gaming adaptation for students of a methodology course for written and oral expression Paper activities are carried out in the classroom and Moodle activities are performed individually outside of the classroom.

\subsection{Method}

Participants. The participants were $1761^{\text {st }}$ year science students from a French public university, distributed into ten groups initially composed of 13 to 20 students. They were following a class to help improve and develop their writing skills in French, in particular in science, where writing correctly can be an issue even for some university-level students, foreign or not. The number of participants has fallen sharply 
because some students dropped the class and others did not receive some mandatory e-mails for the experiment. Finally, the 98 considered students are 19 years old on average and $53 \%$ of them are women. Each participant was randomly assigned to one of the four following conditions:

[c] No adaptation (control group): 29 students

[g] Gaming Adaptation: 26 students

[d] Didactic Adaptation: 24 students

[gd] Gaming and Didactic Adaptation: 19 students

Material. The participants answered two surveys before the experiment. The first one (pretest) was a knowledge test based on scores from 0 to 1 on six areas: spelling, grammar, syntax, time concordance, conjugation and vocabulary. It was built by one of the teachers. The second survey was the BrainHex test [16], returning scores from 10 to 20 on seven player types: Seeker, Survivor, Daredevil, Mastermind, Conqueror, Socializer et Achiever. The validity of the Brainhex typology and survey was investigated recently. Busch et al. [24] measured the internal consistency of each of the seven factors underlying the test with Cronbach's Alpha $(\mathrm{n}=592)$ and found acceptable reliability coefficients. Finally, the participants answered a posttest based on the same six knowledge areas as for the pretest.

In collaboration with teachers, we created 46 paper activities to be used in the classroom and 58 Moodle activities to be used independently. The type of most activities was multiple choice questions, text to be completed and table to be completed. Each activity was made to improve knowledge on one of the six areas. It included zero, one or several gamification mechanics. The integrated mechanics are presented in Table 1.

Table 1. Implemented gamification mechanics.

\begin{tabular}{l|c|c}
\hline \multicolumn{1}{c|}{ Player type } & Classroom activities & Moodle activities \\
\hline Seeker & $\begin{array}{c}\text { Activity based on an article } \\
\text { including scientific knowledge }\end{array}$ & $\begin{array}{c}\text { Activity based on an article } \\
\text { including scientific knowledge }\end{array}$ \\
\hline Survivor & $\begin{array}{c}\text { Activity ending } \\
\text { at an unexpected moment }\end{array}$ & - \\
\hline Daredevil & Limited time activity & $\begin{array}{c}\text { Time and number of trials } \\
\text { are limited }\end{array}$ \\
\hline Mastermind & - & - \\
\hline Conqueror & Competitive activity & - \\
\hline Socializer & Cooperative activity & $\begin{array}{c}\text { Discussion on the forum } \\
\text { included into the activity }\end{array}$ \\
\hline Achiever & - & $\begin{array}{c}\text { A check mark } \\
\text { for each activity achieved }\end{array}$ \\
\hline
\end{tabular}

Procedure. The experiment took place on a four-week period with two hours of class each week. The students had to work on Moodle activities between the classroom 
lessons. The students' distribution into the four conditions ([c], [g], [d] and [gd]) divided each of the ten groups in four sub groups. These steps took place each week:

1. Two days before the classroom session, the classroom recommendations were calculated and sent to the teacher by e-mail.

2. During the first 20 minutes of the classroom session, the students carried out the recommended activities in subgroups.

3. After each classroom session, the students' profiles were updated according to whether they performed the classroom activities or not.

4. The same day, the Moodle recommended activities were calculated and sent to the students by e-mail. Each student was offered two mandatory activities and one optional activity. They were given three days to perform them. They had no recommended activity the fourth week.

5. Three days before the classroom session, the students' profiles were updated according to the score that they obtained on each Moodle activity.

6. The same day, the teachers were informed of the number of mandatory Moodle activities done by their students, in order to take it into account for their mark.

Applying MAGAM. For the group [c], the recommended activities were selected randomly. For the group $[\mathrm{g}]$, the recommendations were based on the calculation $\left(\mathrm{C}_{\mathrm{g}}\right)$ applied to the seven player types. This calculation gives a high recommendation value for the activities with gamification mechanics adapted to the user player types. For the group [d], the recommendations were based on calculation $\left(\mathrm{C}_{\mathrm{d}}\right)$ applied to the six knowledge areas. This calculation gives a high recommendation value for the activities that teach knowledge the learner does not master yet. If the mastery value for a knowledge area $p$ is weak (i.e. $\mathrm{M}_{\mathrm{ua}}$ low) and the activity $a$ teaches this knowledge area (i.e. $\mathrm{Q}_{\mathrm{ua}}$ is high), then the activity is more likely to be recommended (i.e. $R 2_{\text {ua }}$ is high). For the group [gd], the calculations $\left(\mathrm{C}_{\mathrm{g}}\right)$ and $\left(\mathrm{C}_{\mathrm{d}}\right)$ were applied successively and merged using $\left(\mathrm{G}_{\mathrm{gd}}\right)$.

$$
\begin{aligned}
& \forall \mathrm{u} \forall \mathrm{a}, \quad \mathrm{R} 1_{\mathrm{ua}}=\frac{\Sigma_{\mathrm{p}=1}^{7} \mathrm{M}_{\mathrm{ua}} \cdot \mathrm{Q}_{\mathrm{ua}}}{7} \\
& \forall \mathrm{u} \forall \mathrm{a}, \quad \mathrm{R} 2_{\text {ua }}=\Sigma_{\mathrm{p}=1}^{6}\left(1-\mathrm{M}_{\mathrm{ua}}\right) \cdot \mathrm{Q}_{\mathrm{ua}} \\
& \forall \mathrm{u} \forall \mathrm{a}, \quad \mathrm{R} 3_{\mathrm{ua}}=\mathrm{R} 1_{\mathrm{ua}} \cdot \mathrm{R} 2_{\mathrm{ua}}
\end{aligned}
$$

Three selections were used to recommend the Moodle activities. They selected the activities with the higher recommendation values independently for each student. One selection was used to recommend the classroom activities. It selected the activity with the highest average value for all the students of each subgroup, as they had to work on the same activity. During the experiment, the player profiles of the users (player types) were considered as static. However, their learner profiles (knowledge areas) were updated according to their results. After each activity, the value of each knowledge area changed according to this formula: value ${ }_{t+1}=\left(\right.$ value $_{t}+$ score $) / 2$.

When a learner finished an activity, it could no longer be recommended to him/her. 


\subsection{Results}

Results. Table 2 presents the scores obtained by the students of each condition for the pretest and posttest. We took the average value of the six areas to get a score between 0 and 1. The progress of each student was calculated with the formula: progression $=($ posttest - pretest $) /(1-$ pretest $)$. The value reported in Table 2 is the medium progression value of each group. Contrary to the original teacher's expectation, the posttest appeared to be more difficult than the pretest, which explains the negative values of progression.

The difference between each condition was evaluated with a bilateral Student ttest. We performed six tests with a 5\% threshold. The participants in conditions [g] and [gd] did not have a progression superior to the control group. Also, the participants in condition [gd] progressed more than the participants in condition [d] $(p=0.034)$. However, after applying the correction of Bonferroni, this difference does not pass the threshold of the test at $\mathrm{p}=0.0085$.

Tableau 2. Progression between pretest and posttest and $\mathrm{p}$ values.

\begin{tabular}{cccccccc}
\hline Condition & $\mathrm{N}$ & Pretest & Posttest & Progression & {$[\mathrm{c}]$} & {$[\mathrm{g}]$} & {$[\mathrm{d}]$} \\
\hline$[\mathrm{c}]$ & 28 & 0.66 & 0.50 & -0.044 & & & \\
{$[\mathrm{~g}]$} & 26 & 0.68 & 0.52 & -0.050 & $\mathrm{p}=0.603$ & & \\
{$[\mathrm{~d}]$} & 24 & 0.66 & 0.48 & -0.058 & $\mathrm{p}=0.190$ & $\mathrm{p}=0.153$ & \\
{$[\mathrm{gd}]$} & 19 & 0.73 & 0.55 & -0.042 & $\mathrm{p}=0.849$ & $\mathrm{p}=0.306$ & $\mathrm{p}=0.034$ \\
\hline
\end{tabular}

For each week, we observed the number of participants who carried out the optional activities (see Table 3). The numbers obtained were compared using a $\mathrm{Khi}^{2}$ test. Only the comparison of conditions [d] and [gd] showed a significant difference $(p=0.006)$ for the first week. This result could mean that the gaming adaptation indeed motivates the learners to carry out more activities. However, further experiments would be required to confirm this observation.

Table 3. Percentage of participants who carried out the optional activity each week.

\begin{tabular}{ccccc}
\hline Condition & N & Week 1 & Week 2 & Week 3 \\
\hline$[\mathrm{c}]$ & 28 & $52 \%$ & $55 \%$ & $50 \%$ \\
{$[\mathrm{~g}]$} & 26 & $53 \%$ & $45 \%$ & $45 \%$ \\
{$[\mathrm{~d}]$} & 24 & $26 \%$ & $40 \%$ & $41 \%$ \\
{$[\mathrm{gd}]$} & 19 & $73 \%$ & $75 \%$ & $62 \%$ \\
\hline
\end{tabular}

\subsection{Discussion}

The participants with didactic adaptation performed a very low number of optional activities compared to the others. We believe this is because calculation $\left(\mathrm{C}_{\mathrm{d}}\right)$ recommended activities on areas that the students did not master, thus the activities that would appear as the most difficult for them. This may have caused a difficulty peak in the beginning that affected the participants' motivation. 
When comparing the gaming adaptation condition $\mid \mathrm{g}]$ with the control one [c], it seems the gaming adaptation failed to increase the students' progression (table 2) or their motivation (table 3 ). However, when the gaming adaptation was merged to the didactic adaptation, it seems the gamification mechanics had a positive impact on the students' performances. This may also be related to the difficulty the students were facing because of the calculation $\left(\mathrm{C}_{\mathrm{d}}\right)$. Thus, the impact of the gaming adaptation is not as clearly identified as in [15]. This could be explained by the lack of a competition mechanic in the Moodle activities (see Table 1), as competition is an important component of many player profiles. It could also be due to the absence of mechanics related to the player type Mastermind.

Concerning the use of MAGAM, this paper brings a proof of concept on its genericity. Indeed, we have presented several adaptation cases from the literature as instantiations of MAGAM. An implementation of this model was used for an unprecedented (to the authors' knowledge) multi-aspect adaptation case, in particular considering the ecological conditions of the experiment.

Although the current implementation of MAGAM is functional, the experiment highlighted some of its limitations, mainly a lack of interoperability. It takes a lot of time to fill the $\mathrm{M}$ and $\mathrm{Q}$ matrices by hand from the survey results and updating them. It also takes time to read the recommendations and send them by e-mail. For its second version, MAGAM should be implemented as a library that would be used into an existing learning environment. The learning environment would automatically fill and update the profiles, and use the resulting recommendations.

\section{Conclusion}

We have presented MAGAM, a generic model that can adapt learning activities according to various aspects of adaptation. Through a brief literature review and an experiment in ecological conditions, we have shown that using MAGAM is a way to adapt learning activities along multiple aspects.

MAGAM is based on the Q-matrix model [21], thus it represents each aspect of adaptation as a simple list of properties. The choice of the Q-matrix model also implies some limitations. For example, it does not represent the prerequisite relations between skills as the Competence-based Knowledge State Theory (CbKST) does. Also, it does not manage uncertainty as Bayesian networks do [25].

Many avenues of research are opening up following this work. First, several extensions could develop and complete MAGAM, such as:

- $\quad$ Limiting the number of times an activity is recommended.

- When there are too much constraints and some users do not have any suitable activity, releasing some constraints automatically.

- Taking into account pedagogical constraints such as the number of students required to work on the same collaborative activity.

The interest of taking into account several aspects of adaptation still has to be empirically tested, as few experiments can be found in the literature. MAGAM should help driving the tests to identify which set of properties and calculations work and 
which ones do not. Upon these findings, another set of experiments could explore which types of mergers and selections give the best results on learning outcomes.

Finally, some work still has to be done to give the teachers access to an interface allowing them to handle this model, as the choice of an operation remains highly technical for now. We should develop a library of calculations, mergers and selections and specifying their semantic in educational terms. For example, a teacher setting the system would not select "a weighted average merger" but rather "an adaptation giving priority to the didactic aspect over the gaming aspect". This effort should come with a more ergonomic management tool.

\section{Acknowledgements}

We would like to thank Sorbonne Universités for funding this research project and teachers, but also students, who accepted to participate to this experiment.

\section{References}

1. Vandewaetere, M., Desmet, P., \& Clarebout, G. (2011). The contribution of learner characteristics in the development of computer-based adaptive learning environments. Computers in Human Behavior, 27(1), 118-130. https://doi.org/10.1016/j.chb.2010.07.038

2. Naik, V., \& Kamat, V. (2015). Adaptive and Gamified Learning Environment (AGLE). In 2015 IEEE Seventh International Conference on Technology for Education (T4E) (p. 7-14).

3. Aleven, V., McLaughlin, E. A., Glenn, R. A., \& Koedinger, K. R. (s. d.). Instruction based on adaptive learning technologies. Handbook of research on learning and instruction. Routledge.

4. Atkinson, R. C. (1972). Optimizing the learning of a second-language vocabulary. Journal of Experimental Psychology, 96(1), 124-129. http://dx.doi.org/10.1037/h0033475

5. Anderson, J. R., Corbett, A. T., Koedinger, K. R., \& Pelletier, R. (1995). Cognitive tutors: Lessons learned. The Journal of the Learning Sciences, 4(2), 167-207.

6. Luengo V., Mufti-Alchawafa D. 2013. Target the controls during the problem solving activity, a process to produce adapted epistemic feedbacks in ill-defined domains. The case of a TEL system for orthopaedic surgery. Workshop on Formative Feedback in Interactive Learning Environments, in conjunction with AIED 2013.

7. Melero, J., El-Kechai, N., Yessad, A., \& Labat, J. M. (2015, May). Adapting Learning Paths in Serious Games: An Approach Based on Teachers' Requirements. In International Conference on Computer Supported Education (CSEDU) (p. 376-394). Springer.

8. Augustin, T., Hockemeyer, C., Kickmeier-Rust, M. D., Podbregar, P., Suck, R., \& Albert, D. (2013). The simplified updating rule in the formalization of digital educational games. Journal of Computational Science, 4(4), 293-303. https://doi.org/10.1016/j.jocs.2012.08.020

9. Walkington, C. A. (2013). Using adaptive learning technologies to personalize instruction to student interests: The impact of relevant contexts on performance and learning outcomes. Journal of Educational Psychology, 105(4), 932.

10. Harley, J. M., Carter, C. K., Papaionnou, N., Bouchet, F., Landis, R. S., Azevedo, R., \& Karabachian, L. (2016). Examining the predictive relationship between personality and emotion traits and students' agent-directed emotions: towards emotionally-adaptive agentbased learning environments. User Modeling and User-Adapted Interaction, 26(2-3), 177219. https://doi.org/10.1007/s11257-016-9169-7 
11.Taub, M., Azevedo, R., Bouchet, F., \& Khosravifar, B. (2014). Can the use of cognitive and metacognitive self-regulated learning strategies be predicted by learners' levels of prior knowledge in hypermedia-learning environments? Computers in Human Behavior, 39, 356367.

12.Mampadi, F., Chen, S. Y., Ghinea, G., \& Chen, M.-P. (2011). Design of adaptive hypermedia learning systems: A cognitive style approach. Computers \& Education, 56(4), 1003-1011. 1003-1011. http://doi.org/10.1016/j.compedu.2010.11.018

13.Bousbia, N., Labat, J. M., Balla, A., \& Rebai, I. (2011). Supervised classification on navigational behaviours in web-based learning systems to identify learning styles. International Journal of Learning Technology, 6(1), 24-45.

14.Natkin, S., Yan, C., Jumpertz, S., \& Market, B. (2007). Creating Multiplayer Ubiquitous Games Using an Adaptive Narration Model Based on a User's Model. In Digital Games Research Association International Conference (DiGRA 2007).

15.Monterrat, B., Desmarais, M., Lavoué, E., \& George, S. (2015, June). A player model for adaptive gamification in learning environments. In International Conference on Artificial Intelligence in Education (p. 297-306). Springer International Publishing.

16.Nacke, L. E., Bateman, C., \& Mandryk, R. L. (2011). BrainHex: Preliminary Results from a Neurobiological Gamer Typology Survey. In ICEC (p. 288-293). Springer.

17.Heilman, M., Collins-Thompson, K., Callan, J., Eskenazi, M., Juffs, A., \& Wilson, L. (2010). Personalization of reading passages improves vocabulary acquisition. International Journal of Artificial Intelligence in Education, 20(1), 73-98.

18.Yarandi, M., Jahankhani, H., \& Tawil, A.-R. H. (2013). Towards Adaptive E-Learning using Decision Support Systems. International Journal of Emerging Technologies in Learning (iJET), 8(S1). https://doi.org/10.3991/ijet.v8iS1.2350

19.Murray, R. C., Vanlehn, K., \& Mostow, J. (2004). Looking ahead to select tutorial actions: A decision-theoretic approach. International Journal of Artificial Intelligence in Education, 14(3, 4), 235-278.

20.Göbel, S., Wendel, V., Ritter, C., \& Steinmetz, R. (2010). Personalized, adaptive digital educational games using narrative game-based learning objects. In 5th International Conference on E-learning and Games (Edutainment 2010) (p. 438-445). Changchun, Chine.

21.Barnes, T. (2005). The q-matrix method: Mining student response data for knowledge. In American Association for Artificial Intelligence 2005 Educational Data Mining Workshop.

22.Desmarais, M. C., \& Naceur, R. (2013). A Matrix Factorization Method for Mapping Items to Skills and for Enhancing Expert-Based Q-Matrices. In International Conference on Artificial Intelligence in Education (p. 441-450). Springer.

23.McCrae, R. R., \& Costa, P. T. (1987). Validation of the five-factor model of personality across instruments and observers. Journal of personality and social psychology, 52(1), 81.

24.Busch, M., Mattheiss, E., Orji, R., Fröhlich, P., Lankes, M., \& Tscheligi, M. (2016). Player Type Models: Towards Empirical Validation. In Proceedings of the 2016 CHI Conference Extended Abstracts on Human Factors in Computing Systems, 1835-1841. ACM Press. https://doi.org/10.1145/2851581.2892399

25.Pearl, J. (1988). Probabilistic Reasoning in Expert Systems: Networks of Plausible Inference. Morgan Kaufmann Publishers, Inc, San Francisco 